\title{
Matchmaking Problems in MOBA Games
}

\author{
Muhammad Farrel Pramono', Kevin Renalda², Harco Leslie Hendric Spits Warnars ${ }^{3}$, \\ Dedy Prasetya Kristiadi ${ }^{4}$, Worapan kusakunniran ${ }^{5}$ \\ ${ }^{1,2}$ Information Systems Department, School of Information Sy stems, Bina Nusantara University, \\ Jakarta, Indonesia 11480 \\ ${ }^{3}$ Computer Science Department, BINUS Graduate Program-Doctor of Computer Science, Bina Nusantara University, \\ Jakarta, Indonesia 11480 \\ ${ }^{4}$ Computer Systems, STMIK Raharja, Tangerang Banten, Indonesia 15119 \\ ${ }^{5}$ Faculty of Information and Communication Technology, Mahidol University, Nakhon Pathom, Thailand
}

\begin{tabular}{|c|c|}
\hline Article Info & ABSTRACT \\
\hline Article history: & MOBA is a popular genre that requires teamwork to achieve victory. A close \\
\hline Received Aug 21, 2017 & $\begin{array}{l}\text { and tight match is what make MOBA fun to play and increase its user } \\
\text { satisfaction, but some factor may ruin the matchmaking and create }\end{array}$ \\
\hline Revised Sep 7, 2017 & unbalanced match between the two team. Those problems factors are high \\
\hline Accepted May 2, 2018 & $\begin{array}{l}\text { latency, players with bad attitude, and players doing unfamiliar role. We use } \\
\text { DOTA } 2 \text { as our case study. Then we compare the DOTA } 2 \text { matchmaking }\end{array}$ \\
\hline Keywords: & $\begin{array}{l}\text { system in other sector to make comparison. Lastly, we discuss about solution } \\
\text { to solve MOBA matchmaking problem such as displaying live information }\end{array}$ \\
\hline MOBA & $\begin{array}{l}\text { about online players, players searching for games, servers online and ETA } \\
\text { for gaming to start. In addition, we proposed new variable to be considered in }\end{array}$ \\
\hline Matchmaking & $\begin{array}{l}\text { the matchmaking system, which are Preferences Role, player's chosen } \\
\text { thes }\end{array}$ \\
\hline MMR & preferences role will be considered while the system set up the game to \\
\hline Balanced Game & minimize the number of unbalanced games in MOBA. \\
\hline
\end{tabular}

Copyright (C) 2018 Institute of Advanced Engineering and Science. All rights reserved.

Corresponding Author:

Muhammad Farrel Pramono,

Information Systems Department, School of Information Systems,

Bina Nusantara university, Jakarta, Indonesia 11480.

Email: muhamad.pramono@binus.ac.id

\section{INTRODUCTION}

Today's games have much evolved from when it was 20-30 years ago when it was simple and mostly single player and games are more likely to be more fun when it's played with other people, friends or even random stranger. At some point, people has started to play games competitively, especially for MOBA games (Multiplayer Online Battle Arena) players such as DOTA 2, HON, LOL, HOTS, etc. [1]. Multiplayer Online Battle Arena is a sub-genre of strategy game. The game consists of two teams, each player controls a single character. The team required a good teamwork and strategy to defeat the opponent [22-24].

They are fun and happy when playing competitively in means of playing a tight match. But, playing against easy enemy or defeated one-sidedly might feel less enjoyable or even gives them unpleasant experiences in that game [2, 18]. It means that the matchmaking is not fair. Matchmaking is a process to air 2 person or more people, in this case of game, 10 people for two teams. Having too many these unfair matchmakings might make them stop playing the game completely [25-27]. For players enjoyment stems from crushing another team the sense of victory getting success and winning is king. Players also described the frustration they feel when they lose "it's frustrating when you're getting beaten and there's no way can you win" and "the frustration comes from losing" [3]. In other words, the aspects of information quality, system quality, and service quality or in this case the matchmaking system, will affect user satisfaction of the 
system [4]. Low user satisfaction might make customer move to other games, which leads to company's revenue lost [5].

Improving matchmaking is the key component for MOBA games to make a better-balanced game. It is important for a competitive games developer to properly set up a fair matchmaking between players and ensure player's satisfaction at optimal level [19-21]. In order, to achieve those result we should get more player's information and choose which information may be related to their skill and how they contribute to the team and taking it into account for better and fair matchmaking system to get better result at matchmaking.

\section{PREVIOUS RELATED WORKS}

Katya Sycara have defined Language Advertisement and Request for Knowledge Sharing (LARKS) for agent advertisement and requests and a matchmaking process that using LARKS. LARKS matchmaking process performs both syntactic and semantic matching and using concept language, Information Technology Infrastructure Library (ITL), to allow the specification of concepts. LARKS matchmaking using five filters, which are context matching, profile comparison, similarity matching, signature matching and constraint matching. Filter selection depends on the user. Using different combination of filter could be resulting in different result [6].

Meanwhile, Jimenez and his team studying about what is the role of gameplay experience and case based recommendation within the matchmaking in non-solo game. The paper discussing about different approaches such as skill based and role based matchmaking. The previous one generating recommendations using player skill rating while the newer one using role configuration to make matchmaking is more interesting [7].

Furthermore, Justin Manweiler and team said that matchmaking mobile system is challenging, because high variable performance of cellular networks and the scalability needs. The team have built a service for matchmaking in mobile game so that the game could be satisfying for player. Before that, they need to solve two problems. First, the service needs to know the latency of the cellular network between players. Next, it needs to group players as fast as possible into viable game session. Within the paper, the team experiments on predicting latency of the cellular network and resulting a better player grouping [8].

Moreover, Matchmaking Game Players on Public Transport is an extension from the previous paper, called GameOn written by Nairan Zhang. It presented about a system that allowed public transport user to play multiplayer game with other public transport user while on the same transportation. The system has a problem with connection. The previous work is focusing on the reliability of the network, while this one, the team answered how to find a better setup for reliability user layer connection (maximizing group coherence degree) [9].

Furthermore, Maxime Véron said that designing and implementing a quality matchmaking service for online multiplayer game requires advanced knowledge of player's behavior. Gathering data for analyze is quite challenging since game server are protected to prevent cheating Maxime and team, gather public data. They present online database that available free, and make analysis and conclusion for the matchmaking service in the paper [10]. Meanwhile Quan Li said that to make a successful Multiplayer Online Battle Arena (MOBA), the ratio of snowballing and comeback that occurred to all matches must be main maintained at some level to be considered as fair game. It is easy to identify those occurrences, but from the perspective from the game developers is difficult. It could have happened because from the data of MOBA games usually is dynamic, so that it has a various result. However, Quan Li's system could identify player's strategy and performance then suggest patterns [11].

Lastly, Christoph Eggert discusses paper about classification of player role in DOTA 2. PC games now considered as one of the big business, which also stated that there is a big growth of interest people for competitive gaming, called as electronic sports. One of which is MOBA (Multiplayer Online Battle Arena) games are one of the well-known game type. To run this team based strategies, the player needs to take very specific role in a team. The paper examining how the supervising machine to classifying player behavior with detail but not well-defined roles in the team of DOTA 2. They provide a detailed discussion for creating complex attributes from low-level data extracted from previous files. Using attribute evaluation technique, they would able to make large set of candidate attributes into a number that manageable. Based fromit, they differ then make discussion about performance of a variety of supervised classification algorithms. The result with 708 labeled players of data set see logistic regression as the most reliable and best performing clas sifier [12]. 


\section{RANKING, LANGUAGE PREFERENCE, AND REGION AS INFLUENCER FACTOR THE MATCHMAKING PROCESS}

Matchmaking process in game is influenced with 3 factors. Therefore, they are ranking, language preference and region. Ranking is applied to group the player based on their game's skill, language preference is used for better communication strategy among players, and region is used for better internet connection purpose.

Firstly, most online game matchmaking system used ranking as the main information for matchmaking purpose, which is known as ELO Rating System. ELO Rating System is a method for calculating skill for calculating skill into numerical rating for player versus player game [13]. Elo System named after its founder, Arpad Elo. This simple system can be applied to many games. Rating system will select players of similar rank from queueing pool and set up a game for them.

Secondly, the other factor considered for matchmaking is the language preferences for game that require teamplay for ensuring that language barrier between players won't dis rupt players to work as a team.

Thirdly, location of the players considered as huge impact, because if the location between players are too vast, then there will be delays in relaying the data from the server to clients and created high latency, which will reduce one's performance. It could have happened because of the lag, so system will automatically set player to the nearest server available although you can also force yourself to play in far server in your own risk.

\section{GAME DOTA 2 MATCHMAKING WORKS}

Defense of the Ancient 2 (DOTA 2) is a popular game from the Mobile Battle Arena Multiplayer (MOBA) genre, MOBA is a genre of a game where a player control one unit from one of the 2 team in an Action Real-Time Strategy (ARTS) game. In DOTA 2, the players will be playing, as one of the 5 heroes from each team, there will be 2 team fighting each other called The Radiant and The Dire as default. Victory in this game achieved by destroying opposing team's Ancient, a building located at each team's base. However, to achieve that, it is required from the player to be able to perform teamwork and good individual play to defeat or at least stall enemy's Defending heroes, creep and defensive structure such as tower first before they can destroy opposing team's Ancient [14].

DOTA 2 uses Matchmaking Rank (MMR) systems, it is a numerical rating system as the indicator of one's skill, where the better the player, the more MMR they will have. A fair match in DOTA 2 is created by matchmaking system with considering the 7 criteria of a balanced game stated by Valve. The Valve is a company behind DOTA 2, which has stated that there are 7 criteria for matchmaking in DOTA 2 and they are [15]:

1. The average MMR of each team should be equal or at least similar with the other team

The skill difference between two rival teams must be minimized and be taken as the most priority. They achieved it by setting up a game where the average Matchmaking Rank (MMR) between both team is equal or at least has minimum difference.

2. The MMR differences of the most skilled and the least skilled individual player should be minimized.

The skill difference between the best and the worst player in a game must be reduced (example: player with 9000 MMR should not be able to play with 3000 MMR players even though the average MMR between the two team is equal. Since the MMR differences is too vast).

3. The MMR of the most skilled player in one team should be equal or at least like in the opposing team. The MMR rating of the most skilled player in one team should be equal or like the MMR rating of the most skilled player in the opposing team. For example, the Highest MMR of one player in one team is 6000 then the highest MMR of one player in the other team should be equal or like 6000

4. The average experiences of one team should be equal or at least similar with another team.

The differences between experience (measured by the number of games played) between the least experienced player and the most experienced player is minimized, it means the level of players in the match shouldn't differ too much.

5. Each team should contain the same number of parties.

For example, the matchmaking system will try to avoid setting up a game of party of 5 against 5 individual players since 5 party players could be friend that are used to play together and thus have better teamwork compared to 5 random strangers put up in the same team together.

6. Players in the same team should have similar language understanding.

Players should be able to communicate within the team using the most common lang uage that most people are capable of so the team can work together, people can pick their language preferences before finding a match.

7. Wait times should not be too long. 
In case of player unavailability, the matchmaking system will be forced to set up a game by lowering their criteria to reduce the finding match waiting time, they will compensate for it by giving superior team less MMR when they win and will lost more MMR they lose, works vice-versa to the inferior team.

Moreover, DOTA 2 game has 3 types of game and they are:

1. Normal game

Normal game does not have numerical MMR so Normal game are less competitive compared to the ranked match, solo game also has a rating although it's hidden, you can only see your skill from Dotabuff.com, a statistical website for DOTA 2 game. Normal match's rating system doesn't use number, instead they group up people in 3 category which are Normal Skill, High Skills, and Very High Skill, players does not gain/loss MMR from this kind of match.

2. Ranked Game

Ranked game is a type of match where players play competitively, the entire 7 rules apply strictly for this type of match. In ranked game, it is required for players to play as good as, what their MMR indicated their skills level to keep the balance between the team and ens ure player's user satisfaction. Ranked MMR for Solo and Party is separated.

3. Arcade Games

Arcade games is a category for mini-games within DOTA 2 game, where you can make a map of your own and can play map made by the community too. The matchmaking criteria does not apply here because this mode is purely for fun only.

\section{RATING SYSTEM IN DOTA 2 GAME}

Rating system is the way to determine a player's skill in a multiplayer game. DOTA 2 game is using the traditional ELO Rating system. ELO rating system is a rating system where you gain point when win and lost point when you lose. This rating system's reliability and adaptability has been proved to be useful for other games, because with little modification this rating system is able to adapt to most games.

MMR gain in DOTA 2 game has MMR score between 1 and 49, and the battle between 2 teams have equality MMR gain or loss, where the winning will get the equal plus MMR score whilst the loose team will get equal minus MMR score. Figure 1 shows the example of battle between The Radiant and The Dire teams, where the winner was the Radiant team. The member of The Radiant team got 25 MMR score, whilst member of The Dire team was minus with 25 MMR score.

Although sometimes the system is forced to set up a game where both team are not exactly balanced to reduce the queue time, at this kind of match the system will make up for this by giving more MMR point to inferior team if they win and harsher MMR point loss for the superior team if they lose [15]. The system will also reduce the MMR point loss when the inferior team lose and give a reduced MMR gain to the superior team. Zenotha did the analysis and found out that DOTA 2 basically take a wager total of 50 MMR from both team. The MMR gain is determined by k-rating used in a game which is 50 (so in a balanced game, the stake is 25 , or $50 \%$ of the k-rating). Reversing the way, the formula is written gives us this equation [16]:

$$
\text { MMR Difference }=400 \log 10(50 / \text { Gain }-1)
$$

Where:

MMR Difference $=$ the average differences between two rival teams

The MMR Difference will be round down if difference $<0$, whilst round up if difference $>0$.

Gain= MMR gain or lost after finish the battle game

From this equation, we could presume that the superior team will wager more MMR score than the inferior team. The winning chance of a team is calculated by this equation [17]:

Win chance $=\mathrm{Mg} * 2$

Where:

$\mathrm{Mg}=$ MMR gain

Win chance $=$ Possibility of winning the game.

- If $\mathrm{Mg}<25$ the win chance belongs to inferior team

- If $\mathrm{Mg}>25$ the win chance belongs to superior team

- If $\mathrm{mg}=25$ both team has equal chance to win (50:50)

To calculate the opposing team's winning chance simply use

Team $A=100 \%$ - Team B Winning Chance 


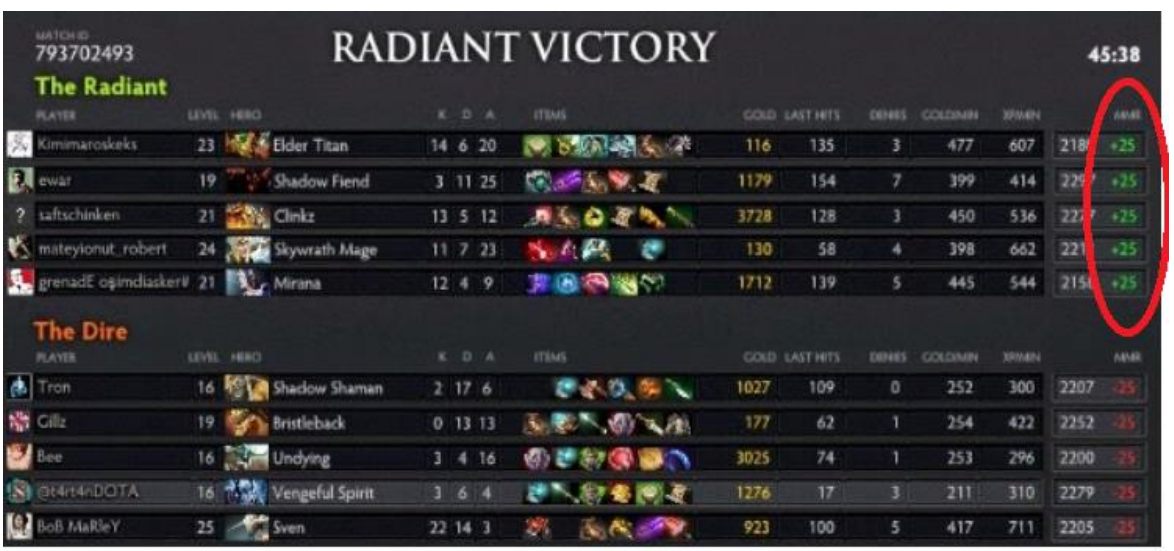

Figure 1. Equality MMR Gain/Loss Between 2 Rival Teams

Although in this case DOTA 2 games does not reveal the possibility to win or how the calculate the win chance of a teambecause that would discourage player before they play. The only possible thing to do is to calculate the possibility after the game has ended and DOTA 2 games shows how many MMR you gain/loss, only after that you will be able to calculate the win possibility. Figure 2 as the example of unbalanced match and based on the calculation in equation (2), where Win chance $=36 * 2=72$ and then there are $72 \% \mathrm{~W}$ in chance of the superior team to win the game, whilst $28 \% \mathrm{~W}$ in chance for inferior team.

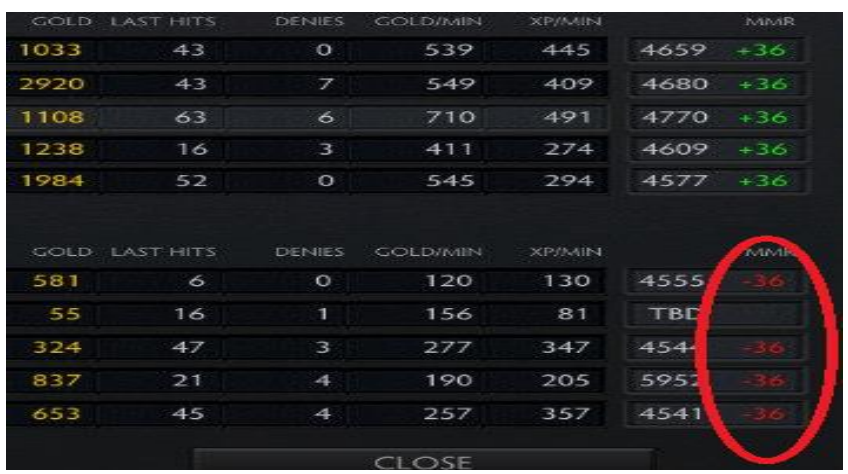

Figure 2. MMR Loss from an Unbalanced Match where inferior team Win

\section{MATCHMAKING PROBLEM}

Based on what have been discussed in previous section. which influence the matchmaking process, but there is still unfair matchmaking process such as unbalanced player skill. Next, the indications as unbalanced game and they are:

1. Short match duration game, where the common game has approximately 30 to 40 minutes game playing time. Figure 3 shows the example from game DOTA 2, where game between Evil Geniuses and Team Liquid, which was ended in 17.14 minutes and recognized as short match duration game.

2. Unbalanced opponent, where the matchmaking process setup the game with much different team's skills. For example, Figure 4 shows unbalanced math with the chart as an example in game DOTA 2 where team Liquid much stronger than team Evil Geniuses, where team Evil Geniuses never win from team Liquid. Meanwhile, Figure 5 shows the balance match with the chart as an example in game DOTA 2 where both teams had a chance to beat others. The chart is created in $\mathrm{x}$ and $\mathrm{y}$ values, where $\mathrm{x}$ value is a time to play and $y$ value is number of Gold and XP.

3. Too many differences in killing score between the two teams, where Figure 3 shows the example from DOTA 2 game where team Evil Geniuses and Liquid have killing score 1 and 24 respectively, where 1 and 24 have too many gaps killing score. 


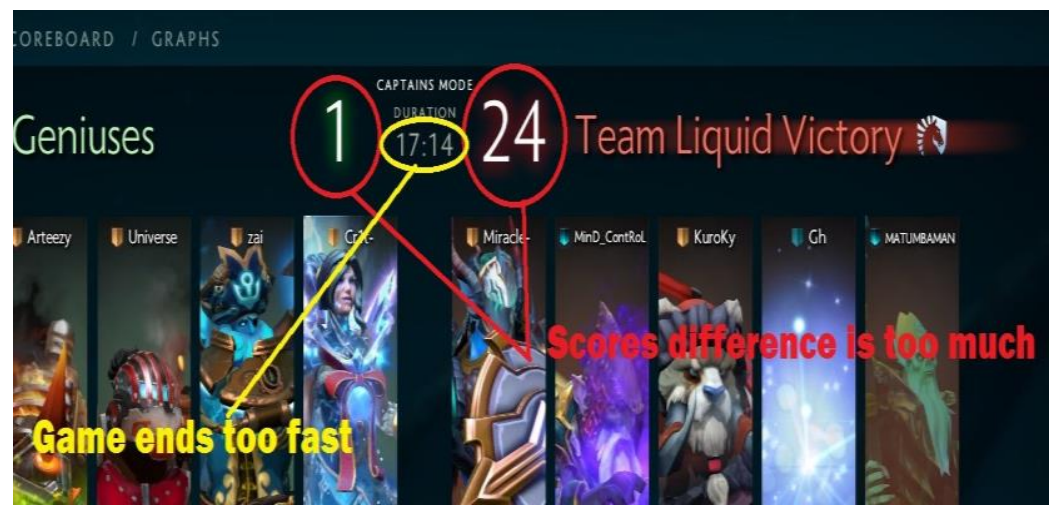

Figure 3. Example of the Scores and Finish Time of an Unbalanced Match

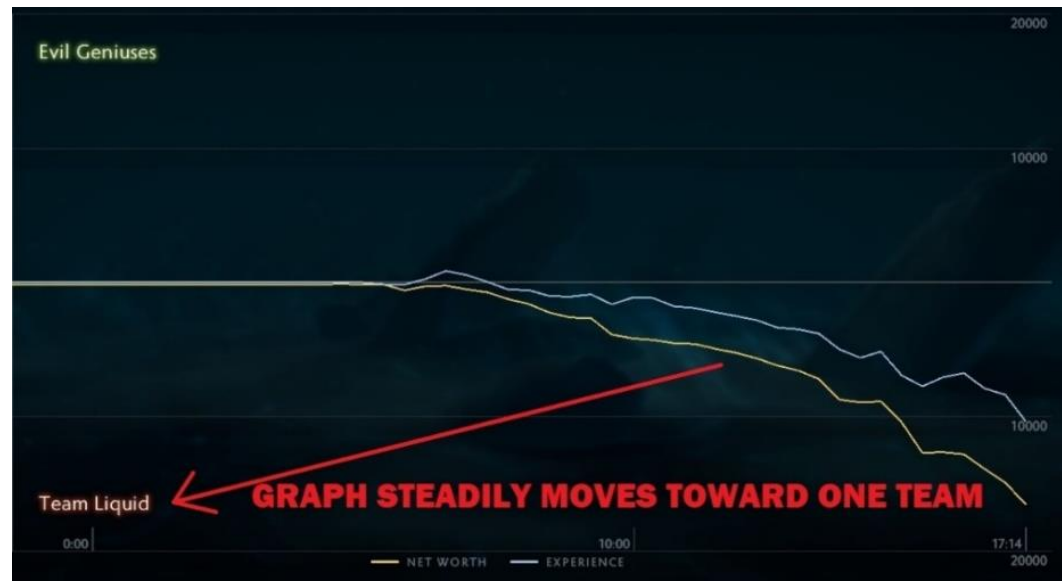

Figure 4. Example of Unbalanced Match with Chart of Gaining Gold and XP in DOTA 2 Game Between Team Evil Geniuses and Team Liquid

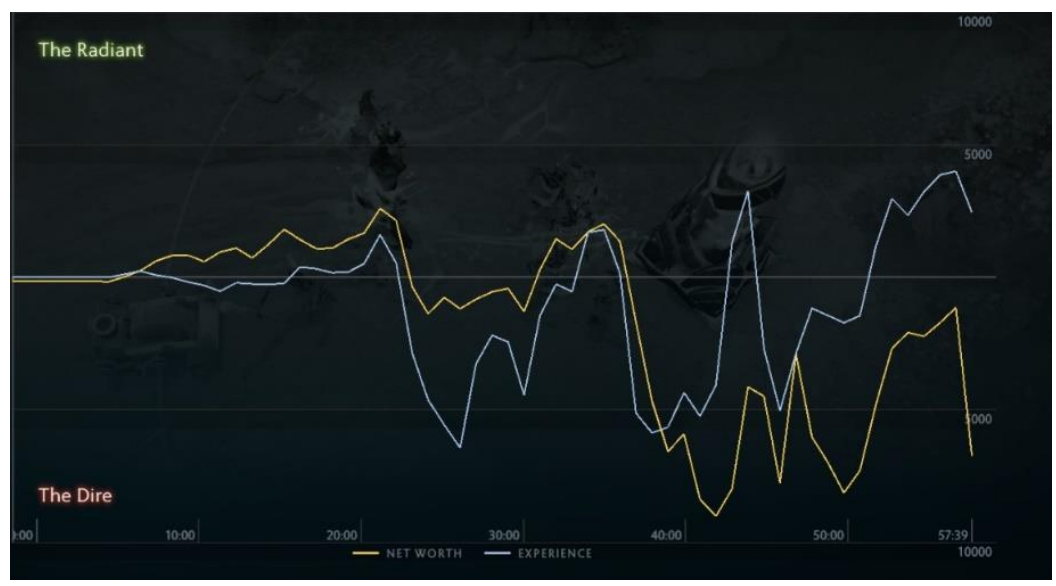

Figure 5. Example of Balanced Match with Chart of Gaining Gold and XP in DOTA 2 Game Between Team Radiant and Team Dire Moving Up and Down

In this paper, we are interest to discuss matchmaking problems, which are not part of internal game problems and specific to discuss as external matchmaking problem. External matchmaking problem is a 
problem, which influence the player score performance from the outsider perspective game as a system. There are four external matchmaking problems, which affected to most matchmaking system:

1. Lack of quantity players online number

At certain time, there is possibility that not enough players with similar skills are in the queueing pool, especially for higher rank player since they are few in number. There has been a case in DOTA 2, where high ranked player waited for more than 2 hours for the system to set up a game, but nothing happens. This is because all the other higher-rank players are involving in international tournament for players from all around the world, where they play in different regions. In this case DOT A 2 game will set him up with player with lower rank and arrange the players so the average MMR of both team will be equal or at least similar.

2. Players with bad attitude

One of factor that an unfair match happening, a player with bad attitude will play poorly to lose purposely, which will damage the user satisfaction for other player especially for their teammates that will be at disadvantage because of this. The reason players doing this are various, for example someone throwing the game on purpose, becaus e he/she does not get his/her favorite role. Throwing a game is a term in the MOBA community for playing badly to lose on purpose.

3. High Latency

High latency also could come from the external factor. The high usage of the same network will have ended up stressing up the network which resulting in high ping or high latency. This will delay the action inputted by player thus affecting their gameplay.

4. Doing unfamiliar role

There are multiple roles in DOTA 2 games which each role has it's own style and mindset to master it. It is hard to master all roles in DOTA 2 since every role has distinct features and characteristic that player needed to adapt to fully utilize the role. Most of player in DOTA 2 game prefer to play in the roles that they excel in or familiar with, rather than the roles that they are not good at and it is causing problem. Playing a game with unfamiliar role, will reduce player's performance and will increase the chance of losing MMR point.

\section{MATCHMAKING IN OTHER SECTOR}

Matchmaking is not only available in the gaming sector but also in another sector. For example, dating or chatting site like Omegle or Tinder, both simply pairs up two random strangers together to chat with each other, but today's tinder has added tags features so people can choo se what they want to talk about so the 2 strangers will have the same interest in something to talk about it.

Figure 6 shows Omegle application where it is a random chatting website that could adds up topic or interest of a chat. In this case, figure 6 shows that this person who uses the Omegle wanted to talk about chocolates, shopping, watching tv, and cricket so the system would match him/her with the person who has the same interest or hobbies.

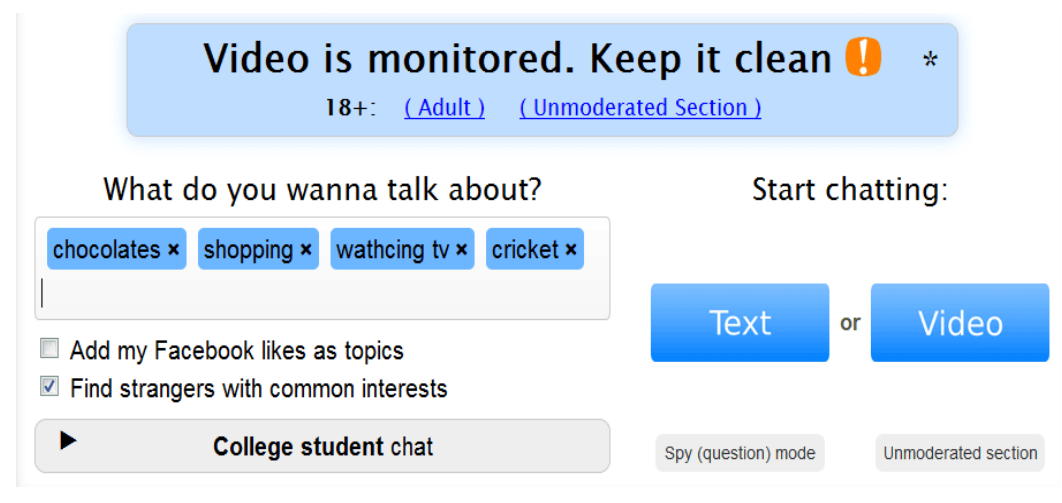

Figure 6. Chat by Preferences in Omegle (omegle.com)

While Omegle using variable such as location and interest, Tinder mobile application as shown in Figure 7 adds up gender, hobby as the variable. So, the system will suggest opposite gender, connect hobbies. Tinder is similar with Omegle, but it is an mobile application based chat.

Indonesian J Elec Eng \& Comp Sci, Vol. 11, No. 3, September 2018 : 908 - 917 


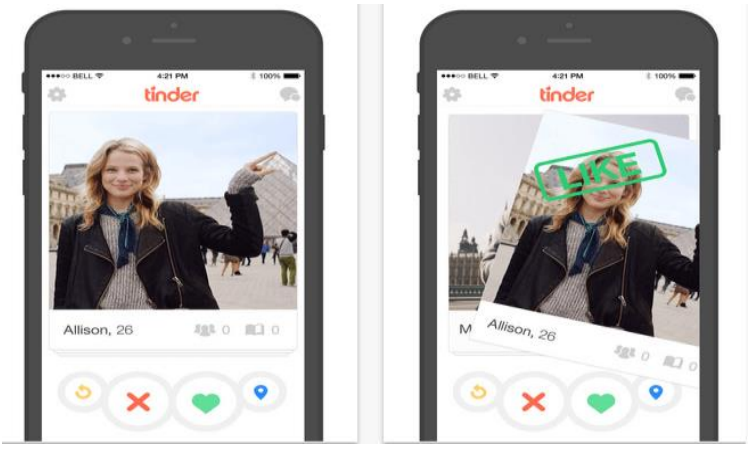

Figure 7. Chat by Perferences in Tinder (tinder.com)

Moreover, Tinder is an app that paired up people from nearby location. Tinder does not have any preferences or special matchmaking method. It just simply displays people nearby the user and if user liked someone and the other person liked the user back, as in Figure 7, they can chat to know each other more.

The differences from both system is that game matchmaking system is used to make a fair match while dating/chatting matchmaking system is simply used to pair people with each other solely by preferences, while games matchmaking will require a lot of calculation and equation in other to bring the most balanced match possible. Chatting/dating matchmaking only require personal preferences of both people aligned with each other so they have the same topic interest to talk about. Therefore, we could implement similar preferences system from tinder and Omegle to DOTA 2 game but it should work the other way around by separating the player with the same preference. To avoid people with the same role specialization ended up in the same team.

\section{MATCHMAKING DISCUSSION}

After considering the information from previous sections, we have discussed that the problem we identified from section 5 can be minimized by using our suggestion, which are:

1. Lack of players online

Deficiency in player with similar rank is a complex problem. Both writers already discuss and the best way to solve it only with display warning for lacking player, also while waiting for ranking game, system will display players online, player who searching game, and server online. By having those three information, system will calculate Estimate Time Arrival (ETA) as shown in figure 8, particularly for information Expected Wait Time. This system already applied in Counter Strike: Global Offensive game. This is important because player prefers to easily get fast and accurate information [18] so player will get won't waste their time waiting in case the system require long time for arranging a match.

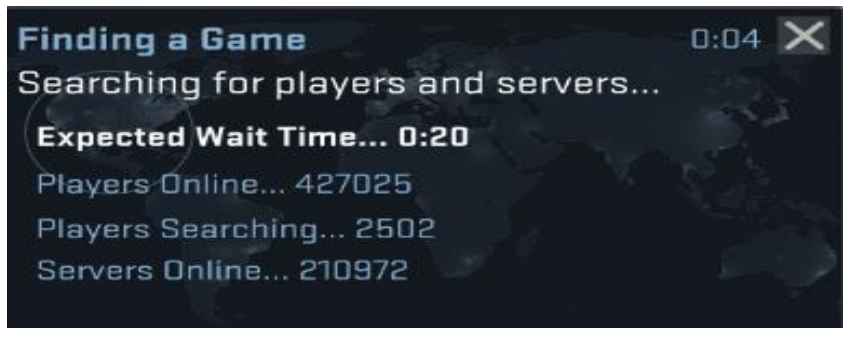

Figure 8. The Example of Information Display to the Player While Waiting to Join the Game it shows the Finding Game Estimation Wait Time, Current Number of Online Player, Number of Players Searching a Match, and Number of Server Available

2. Player with bad attitude

Most MOBA games already provide report system to report this kind of player, player can report other player for being a bad attitude player and later will be assessed by the MOBA team to find out if the 
report were true or not by checking the recorded match. Here is the example of DOTA 2 game report categories:

1. Flaming

Using chat abusively to disrespect another player, for example by blaming them or insulting them.

2. Intentional ability abuse

Intentional ability abuse which for people who use their hero ability for trolling (for example: teleporting your teammate to the middle of the enemy team to purposely to kill your own teammate)

3. Intentional feeding

Intentional feeding for people who intentionally let the enemy team kill themselves so the enemy get gold and experience lead, this will break the game balance and reduce user satisfaction.

DOTA 2 game punishment for flaming is usually the playing will be banned from chatting for 24 hours or more, while if someone fall to one of two other 2 criterias the players will be punished by playing Low Priority Match where the queue time is long and the players in that match is usually full of player with bad attitude.

3. High Latency

Gaming while having high ping will affect player's performance. So, we propose to spread even more server across the world to reduce the high latency in-game, especially at the most populated region such as South-East Asia server and peak hours of MOBA for example on Saturday night or when the MOBA games held an event where server tend to be overloaded with players. But it is also possible that high latency is caused by player's own poor network connection, in this case we proposed to give them warning to let them know that their connection is unstable when they try to find a match so the player could check or fix their connection first before they play.

4. Doing unfamiliar role

Frequently, the matchmaking system matched up people that specializes in the same role. While picking role, teammates ended up into picking the same role, which resulting team having deficiency in another role. Therefore, we proposed to use the preferences system as they have in Tinder or Omegle, except in Omegle they set up the people with the same preferences, games matchmaking should to the opposite. We should not let too many people with the same Role preferences in the same team so the team will not lack with player that specialize in other role and remain balanced. We will create a preferences system which players are able to choose more than one of these roles.

Having different role in MOBA games is a big disadvantage as in not having strategic positioning for competition in business organization. The information system itself should be providing a good information as the key for winning the competition [19]. So, Information System for business have challenge for making profit, while game information system should make not only profit, but also fun and entertained for the user [20].

\section{CONCLUSION}

Multiplayer Online Battle Arena (MOBA) is a subgenre of real time strategy, this sub-genre allows you to play as one member of the team and require complex teamwork to achieve victory. A fair and tight match is the key for user satisfaction in MOBA. Better Matchmaking system is the only ensure the match are fair and balanced, but there is some problem such as lack of players online, players with bad attitude, high latency, and too much people who specialize the same role in the same team.

Both writers already discussed about this research and we conclude that reducing unfair match is possible. Although it's hard due to completely exterminate unfair match because of unexpected factor such as: lack of player online, players with bad attitude, high latency and having people play unfamiliar role.

To solve the first problem, we proposed to implement an Estimation display that shows the info about the Number of player online, number of player searching a match, number of server available and estimation waiting time.As for the second problem, we urge to improve the report system and give harsher punishment for player with bad attitude to reduce the number of player with bad attitude.

Thirdly we propose to increase the number of server especially in the place with most player like Southeast Asia server that usually overloaded during Saturday night or event. A warning system to warn the players in case it's their own poor network that is at fault is also important so the user can fix their network before playing.Lastly, we propose to implement a new preferences system that allows player to choose their preferable role before finding a match and preventing too much people with the same role ended up in the same team and forced them to pick other role. 


\section{REFERENCES}

[1] W. Werner, F. Ryffel, T. V. Pape, and V. Karnowski, "The Development of Video Game Enjoyment in a Role Play ing Game ," Cyberpsychology, Behavior, and Social Networking, vol. 16, no. 4, pp. 260-264, Apr. 2013.

[2] W. Kuipers, "Improving matchmaking with game data,",Bachelor Thesis, Radboud University, Netherlands 2016.

[3] D. Johnson, L. E. Nacke, and P. Wyeth, "All about that Base," Proceedings of the 33rd Annual ACM Conference on Human Factors in Computing Systems - CHI 15, pp. 2265-2274, 2015.

[4] Yosep., "Analysis Of Relationship Between Three Dimensions Of Quality, User Satisfaction, And E-Learning Usage Of Binus Online Learning" CommIT (Communication \& Information Technology), vol. 10, pp. 67-72, 2015.

[5] A. Wijaya and A. S. Girsang, "The Use of Data Mining for Prediction of Customer Loyalty," CommIT (Communication \& Information Technology), vol. 10, pp. 41-47, 2016.

[6] K. Sycara, M. Klusch, S. Widoff, and J. Lu, "Dynamic service matchmaking among agents in open information environments," ACM SIGMOD Record, vol. 28, no. 1, pp. 47-53, Jan. 1999.

[7] J. Jiménez-Rodríguez, G. Jiménez-Díaz, and B. Díaz-Agudo, "Matchmaking and Case-based Recommendations ," Proceedings of the ICCBR 2011 Workshops, pp. 63-62, 0ADAD.

[8] J. Manweiler, S. Agarwal, M. Zhang, R. R. Choudhury, and P. Bahl, "Swi2tchboard: a matchmaking system for multiplayer mobile games," Proceedings of the 9th international conference on Mobile systems, applications, and services - MobiSys 11, 2011.

[9] N. Zhang, Y. Lee, and R. K. Balan, "Matchmaking Game Players On Public Transport," Proceedings of the 2nd Workshop on Mobile Gaming - MobiGames 15, pp. 31-36, 2015.

[10] M. Véron, O. Marin, and S. Monnet, "Matchmaking in multi-player on-line games: Studying user traces to improve the user experience.," Proceedings of Network and Operating System Support on Digital Audio and Video Workshop - NOSSDAV 14, 2013.

[11] Q. Li, P. Xu, Y. Y. Chan, Y. Wang, Z. Wang, H. Qu, and X. Ma, “A Visual Analytics Approach for Understanding Reasons behind Snowballing and Comeback in MOBA Games," IEEE Transactions on Visualization and Computer Graphics, vol. 23, no. 1, pp. 211-220, 2017.

[12] C. Eggert, M. Herrlich, J. Smeddinck, and R. Malaka, "Classification of Player Roles in the Team-Based Multiplayer Game Dota 2," Entertainment Computing - ICEC 2015 Lecture Notes in Computer Science, pp. 112-125, 2015.

[13] C. Neumann, J. Duboscq, C. Dubuc, and A. Engelhardt, "Assessing dominance hierarchies: validation and advantages of progressive evaluation with Elo-rating," Animal Behaviour, pp. 911-921, Dec. 2011.

[14] M. E. Glickman, "A Comprehensive Guide to Chess Ratings," American Chess Journal, vol. 3, pp. 59-102, 1995.

[15] A. Ahmad., "How Dota 2 MMR Works - A Detail Guide", 2015. [Online]. Retrieved May 27, 2017, from http://www.dotainternational.com/how-dota-2-MMR-works /

[16] Zenotha ., "Reverse-Engineering the effects of Average Team MMR on winrates," DotA2, 2015. [Online]. Retrieved May 27, 2017, from: https://www.reddit.com/r/DotA2/comments/2dfjge/reverseengineering_the_effects_of_average_team/.

[17] Sylencia., "How much MMR am I risking? (Approximately)," DotA2, 2016. [Online]. Retrieved May 27, 2017, from: https://www.reddit.com/r/DotA2/comments/3zf7pv/how_much_mmr_am_i_risking_approximately/.

[18] R.F. Malik, R. Efendi and E.A. Pratiwi, "Solving Hashiwokakero Puzzle Game with Hashi Solving Techniques and Depth First Search", Bulletin of Electrical Engineering and Informatics, vol. 1, no.1, pp. 61-68, 2012.

[19] R.D. Agustin, A. Purwarianti, K. Surendro and I.S. Suwardi, "Computing Game and Learning State in Serious Game for Learning”, TELKOMNIKA (Telecommunication, Computing, Electronics and Control), vol. 13, no.4, pp. 1422-1436, 2015.

[20] T.S. Gunawan, B. Bahari and M. Kartiwi, "Development of Educational Game for Primary School Mathematics using Microsoft Kinect”, Indonesian Journal of Electrical Engineering and Computer Science, Vol. 6, No. 2, pp. 457-463,2017.

[21] Z. Guoyun, "Game Analysis of Cooperative probability betwwen Alliance Partners", TELKOMNIKA (Telecommunication, Computing, Electronics and Control), vol. 11, no.12, pp. 7284-7289, 2013.

[22] I. Lestari and T. Ratnaningsih, "The Effects of Modified Games on the Development of Gross Motor Skill in Preschoolers", International Journal of Evaluation and Research in Education (IJERE), Vol.5, No.3, pp. 216-220, 2016.

[23] J.A. Abubakar, A.A.Mutalib and D. Permadi, "Design and Development of Curious Jojo@ A Go-Green 3D Game on Android", TELKOMNIKA (Telecommunication, Computing, Electronics and Control), vol. 11, no.6, pp. 3123 3129, 2013.

[24] T.Malinovski, M. Vasileva and V. Trajkovik, "Students' Perceptions during Integration of Computer Games in Primary Education: QoE Analysis", International Journal of Informatics and Communication Technology (IJICT) Vol.3, No.1, pp. 13-22, 2014.

[25] L. Elaachak, A. Belahbibe and M. Bouhorma, "Towards a Sy stem of Guidance, Assistance and Learning Analy tics Based on Multi Agent System Applied on Serious Games", International Journal of Electrical and Computer Engineering (IJECE) Vol. 5, No. 2, pp. 344-354,2015.

[26] H. Setiana and S. Hansun, "Gamified Android Based Academic Information System", International Journal of Evaluation and Research in Education (IJERE), Vol.6, No.2, pp. 164-173,2017.

[27] A. Maseleno, M.M.Hasan, M. Muslihudin and T. Susilowati, "Finding Kicking Range of Sepak Takraw Game: Fuzzy Logic and Dempster-Shafer Theory Approach", Indonesian Journal of Electrical Engineering and Computer Science. Vol. 2, No. 1, pp. 187-193,2016. 